\title{
Generación líquida. \\ Transformaciones en la era 3.0
}

\section{Dra. Silvia Patricia López González}

Esta breve pero sustanciosa obra póstuma de Zygmunt Bauman autor de la teoría del la modernidad líquida es producto de un dialogo epistolar ameno y fluido que mantuvo durante dos meses con un joven periodista italiano 60 años menor que él de nombre Thomas Leoncini.

La obra aporta un conocimiento sobre nuestra realidad, nos lleva de la mano para entender cómo se dieron las transformaciones sociales que hoy, en mucho de los casos evidenciamos como conflictos.

A través del dialogo que mantienen los autores, podemos hacer un ejercicio de interpretación sobre esta era del conocimiento que nos toco vivir y convivir, por cierto, es por su propia naturaleza de aldea global, por lo que presenta los mismos conflictos en cualquier rincón del mundo.

A través de su lectura logramos entender que el origen de nuestros mayores problemas sociales tiene que ver con ese afán de pertenencia al ámbito social sin procurar dotar de sustancia la parte individual, por lo que se crea un espejismo, queremos ser invisibles en lo individual y vernos reflejados en lo social. Entonces si ese todo se conforma de la nada, nos sentimos desamparados al no poder encontrarnos y rescatarnos en ese mundo liquido.

Los autores propician con la lectura de su obra, la reflexión sobre la evolución de la sociedad y los cambios tan evidentes que se han dado en las últimas generaciones. Nos hablan de hechos y situaciones tan comunes y cotidianas que a simple vista cuesta entender la profundidad de los temas, que acto seguido nos apuntan.

Hablar sobre las transformaciones en nuestra piel, la agresividad, las expresiones de sexualidad y amor, nos envuelve en una cotidianeidad que pasa desapercibida, y no es, sino con su persistente visión, como nos permiten entender el punto de vista de dos generaciones: La del maestro y la del alumno, uno de ellos que mira a lo lejos el paso del tiempo y otro que la vive en plenitud; el 
maestro habla de lo que fue y el alumno habla de cómo es y será; uno con tanto por narrar y otro con tanto que crear e imaginar.

Es este el regalo mágico que nos ofrece el gran sociólogo polaco Zygmunt Bauman, catedrático emérito de Sociología de la Universidad de Varsovia, profesor en las universidades de Leeds, Tel Aviv y en la London Shcool of Economics, en su obra póstuma: Un libro simbiótico que muestra la realidad de dos mundos plasmados por los autores.

En tal sentido, la lección expuesta en ésta obra tiene que ver con que las transformaciones de la sociedad en la época posmoderna no debe enfocarse en el problema de las diferencias entre las generaciones, sino su convivencia contemporánea en el mismo mundo.

La convivencia entre lo que fue y lo que es, entre lo viejo y lo nuevo, entre el que soy y aquel que tendré que ser; es ahí en donde está el problema, ya que el nuevo ciudadano no carga con esa bolsa llena de valores y prejuicios y para él no representa nada lo anterior, prefiere lo nuevo, lo liquido, mientras menos peso cargue es mejor, por ello el fenómeno de la continuidad y discontinuidad representa el gran reto de nuestra sociedad.

Pero Zygmunt Bauman, tal como lo expresa el joven periodista en esta obra: confirmó durante su extraordinaria existencia que si existe el progreso, si existe la historia, es gracias a la dialéctica entre continuidad y la discontinuidad. Todos pasamos o hemos pasado por alguna de estas definiciones dicotómicas. Por lo que la proliferación de la lucha generacional no es más que un engaño.

Las estadísticas sobre la estética en el mundo, que es sin duda, un reflejo del ámbito cultural y colectivo, refiere que casi la mitad, esto es: el $47 \%$ de los millennials que son los nacidos entre 1980 y 2000; y más de un tercio: el 36\% de la generación X, comprendida entre los nacidos a mediados de los años sesenta y finales de los setenta o inicios de los ochenta, tienen al menos un tatuaje. En cambio, tan sólo el 13\% de los hijos del baby boom, que son los nacidos entre 1946 y 1964 lo tienen.

Lo cual refleja de manera muy clara y evidente el cambio entre generaciones, tal como lo refiere Thomas Leoncini: "El nativo líquido se mueve hoy solo en el seno de su propia individualidad y se afana por hacerla notoria para invadir la esfera pública, creyendo vanamente en la posible existencia de una solución 
universal y compartida por todos a su ser incompleto”.

Al respecto Zygmunt Bauman explica que: "Todas las modalidades emuladoras de manipulación del aspecto publico en el propio cuerpo nacen de la moderna reelaboración humana, demasiado humana de la identidad social, que pasa de ser un dato a convertirse en una tarea: tarea que actualmente se espera y se considera necesario y vinculante que lleve a cabo su portador individual, mediante el empleo de modelos y materias primas proporcionados socialmente, en una compleja operación de <<reproducción creativa $>>$ que aparece con el nombre de moda".

Por otro lado, separación, marginalidad y agregación son las tres fases que en opinión de Arnod van Gennep, -según refiere Thomas Leoncini- son las que experimenta la victima de acoso, violencia que según lo explica Bauma: $L a$ designación de un enemigo y la demostración a toda costa de su inferioridad es la otra cara inseparable de la moneda de la identificación del yo. No existiría un nosotros sin un ellos.

En relación a la sexualidad y al amor, cómo lograr desprenderlos de la llamada sociedad de la red, que aparece como una combinación de grandes expectativas y frustradas esperanzas en donde el ciber acoso y la difamación son el pan de cada día. "Vivimos en la sociedad de la red, en todo momento, veinticuatro horas al día y siete días a la semana, al alcance de millones de propietarios/usuarios de todas las edades, en cualquier situación, en el bolsillo o en el bolso, pero la mayor parte del tiempo en a mano. Por mucho que podamos estar y/o sentirnos solos, en el mundo online estamos siempre potencialmente en contacto, el mundo offline, sin embargo no ha desaparecido, pero ahora existen dos mundos, netamente distintos uno de otro, pero lo malo es que buscamos el mundo online para salir del mundo estresante y angustiante de la realidad y logramos encontrar un espacio de espléndido aislamiento. En la modernidad líquida, la ansiedad y a depresión han aumentado de forma notable, y la cura de esos males típicos podría ser justo la invisibilidad".

Tal como lo expresa Bauman: En el momento en que te enamoras es probable que no te contentes con una sola noche de amor: querrás más, mucho más. Querrás que ese amor, maravilloso regalo del destino, se cristalice, dure para siempre, el problema es que ese querer que "dure para siempre” implica, al 
menos en ese momento, nada más y nada menos que una decisión y una promesa, a la propia pareja y a uno mismo de amor eterno. Y desde ese momento en adelante decides nadar a contracorriente. Después de todo, contraes ese compromiso, esa obligación, en un mundo totalmente entregado al visto y no visto, al atrapar las oportunidades fugaces, de breve duración y eminentemente revocables. ¿Existe un modo de conciliar el amor hasta que la muerte nos separe con la curiosidad, la intensidad, el desparpajo y, en conjunto, la inquietud de una criatura como esta, hija de una sociedad como esta?

Thomas distingue entre amor y deseo, diciendo que el deseo es un impulso que destruye, o mejor, un impuso de autodestrucción. El amor, en cambio es el deseo de cuidar el objeto que se ama. Si el amor quiere consumir, el amor quiere poseer, dice. El deseo es auto destructivo, pero la protección que el amor teje alrededor del objeto que ama acaba por esclavizar al objeto amado. El amor arresta a su prisionero y lo vigila, lo arresta para protegerlo, pero los nativos líquidos se han convertido en profesionales de la flexibilidad sexual. El amor líquido razona de aquí a las "eternas" veinticuatro horas siguientes.

\section{Bibliografía}

Generación Líquida

Transformaciones en la era 3.0

Bauman, Zygmunt

Leoncini, Thomas

Editorial Paidós

Primera edición impresa en México: abril de 2018

ISBN: 978-607-747-489-0 